\title{
Urology Virtual Education Programs During the COVID-19 Pandemic
}

\author{
Michael Smigelski ${ }^{1}$ (D) $\cdot$ Miyad Movassaghi ${ }^{1} \cdot$ Alexander Small $^{2}$
}

Accepted: 15 October 2020 / Published online: 22 October 2020

(C) Springer Science+Business Media, LLC, part of Springer Nature 2020

\begin{abstract}
Purpose of Review This article aims to describe the impact of the COVID-19 pandemic on American urology trainees, with a focus on virtual learning initiatives.

Recent Findings Urological education was forced to rapidly adapt to the COVID-19 pandemic in 2020. Significant challenges included quarantines, redeployment of residents and faculty, and suspension of regularly scheduled conferences. In response, urologists across the country adopted web-based platforms to develop virtual lecture series to fill the gap. Popular programs for residents included UCSF's COViD (Collaborative Online Video Didactics) series and the New York Section of the American Urological Association's EMPIRE (Educational Multi-institutional Program for Instructing REsidents) series.

Summary Virtual education programs have enabled urology trainees to pursue their education during the pandemic. While the long-term impact of the pandemic on urology training remains unknown, some good may be found in the innovative solutions that have arisen in urology education.
\end{abstract}

Keywords Medical education $\cdot$ COVID-19 $\cdot$ Virtual learning $\cdot$ Residency $\cdot$ Burnout $\cdot$ Wellness

\section{Introduction}

The USA and New York City in particular emerged as epicenters of the global novel coronavirus disease (COVID-19) [1]. In addition to significant loss of life, straining of healthcare resources, and possibly long-lasting economic devastation, normal medical routines were suspended at hospitals across the country. In an effort to conserve healthcare resources, including personal protective equipment (PPE) and hospital beds and staff, surgical procedures were curtailed for months. Meanwhile, residents in surgical training programs were reassigned to overwhelmed emergency departments, COVID-19 wards, and intensive care units.

A nationwide survey of program directors by the Society of Academic Urologists (SAU) published in April 2020 captured the challenges facing academic training institutions and

This article is part of the Topical Collection on Education

Michael Smigelski

ms5209@cumc.columbia.edu

1 NewYork-Presbyterian / Columbia University Irving Medical Center, 161 Fort Washington Avenue, 11th Floor, New York, NY 10032, USA

2 Icahn School of Medicine at Mount Sinai, New York, NY, USA beyond during the height of the pandemic [2]. Of the $45 \%$ of US programs that completed the survey, major disruptions included reserve staffing in $80 \%$, resident redeployment in $26 \%$, and residents under formal quarantine in $55 \%$ of programs. While work hours were modified, patient contact time fell to just 2.1 days per week, and $60 \%$ of programs reported concerns that residents would not meet minimum case requirements. These findings were particularly prominent in states with a high incidence of COVID-19, with $48 \%$ of residents redeployed, $70 \%$ working with COVID-positive patients, and 97\% reporting concerns over exposure and PPE availability. Others fell ill themselves, with estimates of $15 \%$ of residents suffering direct infection and $17 \%$ quarantined [3].

Given the redistribution of urology residents and faculty, many questions arose concerning the future of urology training [4]. In our experience working in Manhattan, both faculty and residents themselves were charged with the task of finding new mechanisms for surgical education. Herein, we explore both the impact of COVID-19 on urological education and the measures that have been created to mitigate that impact on trainees.

\section{Virtual Education in Urology}

COVID-19 disrupted traditional educational experiences for urology residents. Initially, all conferences, including grand 
rounds, tumor board, morbidity and mortality, and didactics, were suspended. However, technologically savvy urologists quickly turned to web-based platforms like Zoom, Citrix Webex, and GoToMeeting to host virtual conferences; residents were also urged to tap into online resources like the AUA Core Curriculum. The use of online education (or elearning) is not new in surgery. In fact, many studies have shown that e-learning can be more effective for adult learners than traditional teaching methods [5].

Efforts to design online learning curricula in urology have generally met with success. Prior to COVID-19, several international platforms had been successfully launched. In 2015, educators working with medical students in Brazil showed that an online "dynamic learning environment" course with surgical videos, urology cases, and basic lectures was superior to a traditional problem-based learning lecture and small group course [6]. The course strengths included high student engagement and satisfaction, high levels of access to content, and more in-depth learning than the traditional approach. Another online course was launched in Sweden in 2015, dubbed "KIUrologyX: Urology As You Like It" [7]. Created for a wide audience, including doctors, students, patients, and lay people, KIUrologyX was intended to promote information about common urological conditions. This course had 4925 participants, of which 514 completed it, and it has since continued at four Swedish medical universities. Of note, the authors estimate that the production cost was approximately $€ 50,000$ and required ten people working full time for 1.5 months to complete the project, highlighting the significant investment of resources that poses a barrier to implementing virtual learning.

In the USA, the American Urological Association (AUA) offers the Core Curriculum, a resource for students, residents, and practicing urologists to study a wide array of topics in the field. The online platform was put in place to provide easily accessible resources for trainees, and it has evolved over time to include articles on topics, seminal references, webinars, surgical videos, and podcasts [8]. Furthermore, virtual course and virtual conference links on the AUA website have made urological education materials more accessible than ever. Residency programs commonly utilize these materials as the basis for educational conferences and board review sessions.

With the clinical and educational slowdown around COVID-19, e-learning rose to the forefront, whereby the aforementioned existing resources were utilized and served as models for novel virtual educational initiatives to emerge [9].

\section{Developing EMPIRE and Other Virtual Education Initiatives}

Given the disruptions, unclear course of the pandemic and potential for future epidemic waves, the development of alternative resident education activities took center stage during the outbreak. Immediately, most urologic residency programs converted their standard conferences to digital platforms [10]. With the use of teleconference and telecommuting software, programs across the country began to provide access to their virtual lectures allowing for participation from across the country. One of the first national programs was the Collaborative Online Video Didactics (COViD) series originating at the University of California San Francisco. The creator of the series, Dr. Lindsay Hampson, set up daily online lectures covering a wide variety of topics from highly regarded faculty across the country. Within weeks, various institutions and subspecialty societies began sharing their own virtual lectures as well (Table 1).

In New York, trainee-led initiatives involving daily lectures from faculty arose from a number of individual programs. With the support of the AUA New York Section, the authors, who were trainees at Columbia and Mount Sinai at the time, collaborated to organize a series of lectures from various faculty and programs within the Section and beyond. This led to the formation of the EMPIRE (Educational Multiinstitutional Program for Instructing REsidents) lecture series. Using social media and section email listservs, expert faculty from NYC and across the country filled the available lecture slots within days. For 2 months during the peak of the pandemic, $2 \mathrm{~h}$ of daily virtual urology lectures provided via Zoom allowed for continued urological education across all urologic sub-specialties.

In addition to being a solely resident/fellow-driven initiative, each EMPIRE urology lecture was preceded by a short "virtual mentoring session" with that session's speaker. Topics included career path insights and advice, COVID19's impact on residency programs, and research opportunities. These daily lectures promoted networking and provided opportunities for viewers to actively participate in question and answer sessions at the end of each lecture. This initiative fostered a sense of community and camaraderie among participants.

These novel virtual education initiatives carried several unique differences from prior virtual education and elearning programs. First, the urgency of the pandemic made them wildly popular for residents who were quarantined, reassigned, or simply not busy. Second, with the cancelation of several national conferences, the virtual education series like COViD and EMPIRE allowed trainees to gain new exposure to faculty outside of their home institutions. Likewise, this increased exposure created networking opportunities through social media and a sense of camaraderie among trainees and faculty. Finally, with new daily content, trainees had the option to tailor their educational experience to their interests, making the online lectures more engaging. 
Table 1 Novel virtual education initiatives

\begin{tabular}{lll}
\hline Sponsor & Lecture series & Focus \\
\hline UCSF & COViD Series (Collaborative Online Video Didactics) & General urology topics for residents \\
AUA NY Section & EMPIRE Urology (Educational Multi-institutional Program for Instructing REsidents) & General urology topics for residents \\
UCSF & PedsUroFLO (Pediatric Urology Fellowship Lectures Online) & Pediatric urology \\
EDGE Consortium & EDGE Talks (Endourology Disease Group for Excellence) & Endourology panel discussions \\
SSMR/SMRU & SMILES (SSMR Male Infertility Lecture Education Series) & Male infertility topics \\
Case Western & Genitourinary Reconstruction Online Learning Series & Reconstruction topics \\
USC & Urology 60 Minutes & Grand rounds broadcast \\
UCI & UCI Urology Grand Rounds & Grand rounds broadcast \\
Intuitive Surgical & Urology Channel Lunch and Learn & Robotic surgery discussions \\
AUA & "AUA Live” Virtual Experience & Online conference \\
\hline
\end{tabular}

\section{Impact of Virtual Education on Trainee Wellness and Mental Health}

The long-term impact of the pandemic on urology training remains unknown, but data are already emerging that highlight strains on resident wellness and mental health. Studies from the USA and abroad show the sweeping changes that residency programs were forced to implement in 2020 and illustrate the emotionally and physically stressful situations into which residents were thrust [4]. These studies also lend insight into the tremendous resilience and bravery of urology residents everywhere.

A survey of 332 American residents evaluated risk factors for anxiety and depression among trainees [11]. The most important risk factors included perception of access to PPE, local COVID-19 severity, personal history of COVID-19 infection, and perception of susceptible household members. Redeployment was reported by $22 \%$ of respondents. Of those that declined redeployment, common cited reasons included concern over reaching graduation case requirements and having susceptible household members or children.

Despite these concerns, adoption of virtual education emerged as one of the most positive changes from this time period. The SAU survey described how programs embraced e-learning as well as virtual mentoring arrangements and even virtual happy hours [2]. Despite half of programs reporting negative impact in their didactics, all reported positive experience with video conferencing for conferences and meetings. The best change that program directors cited was use of nationwide urology virtual didactics. International training programs have also cited the rise in teaching via virtual education and the opportunity to revisit fundamentals of urology as positive outcomes [12].

\section{Future Role of Virtual Education}

Although this bevy of virtual resources has occupied our daily lives and indeed become normative, the question remains: where will we go from here? As operative schedules normalize, patients return to clinics, and labs reopen, the realities of a demanding profession with busy schedules will return. Lecture series archived on the internet will persist as a study tool for urology residents nearing boards or the in-service, but will any other lasting good come from this period of innovation and creativity?

While daily lectures from highly regarded faculty may not be the norm, we would argue that the role of virtual lectures may increase, rather than fade, in importance as normal operations resume. By combining the collective resources of various institutions, residents may be exposed to a higher quality and more varied education. For example, holmium laser enucleation of the prostate (HOLEP) is an effective means for treating voiding symptoms from particularly large prostates, but HOLEP requires a steep learning curve, and many renowned institutions do not have providers experienced in this surgery. Prior to the COVID-19 pandemic, a resident interested in learning about HOLEP would likely need to attend a teaching conference or another institution to acquire any understanding of the procedure. With the availability of crossinstitutional virtual collaborations, however, an expert surgeon in HOLEP might be able to teach hundreds of residents across the country about this surgery at no cost and with minimal loss of training time. Going forward, such collaborations could be arranged for weekly or monthly "virtual grand rounds" to ensure that such a schedule is not overly onerous.

Other possibilities beyond the virtual grand rounds abound. Initiatives such as the EMPIRE Series and UCSF COViD Series have provided a roadmap to create other lasting educational content. Such a roadmap could be used to construct additional didactic materials such as an introductory course 
for interns or more targeted board review materials. The AUA has already adopted the virtual format for the 2020 national meeting, with its highly successful "AUA Virtual Experience" including research presentations, new guidelines plenary sessions, and keynote speakers.

The current spirit of collaboration could be expanded from simple didactics and more cutting-edge programs. For example, cross-institutional research collaboratives could be fostered in order to promote large-scale investigations. Video conferencing capabilities could be expanded to allow for trainee research mentorship across the country. While bench work will always require a physical presence, almost any other urologic research could be carried out by a trainee hundreds of miles from their research mentor.

While the devastation of COVID-19 cannot be denied, some good may be found in the innovative solutions that have arisen in surgical education. Collaboration and a rededication to education have certainly been among the most inspiring parts of this crisis. Whether these will serve to create a lasting impact once the crisis has abated remains to be seen.

\section{Conclusion}

Although the COVID-19 crisis interrupted standard operations and affected thousands of lives, this pandemic has afforded an opportunity to reexamine the routine, traditional mechanisms of urologic training. With minimal surgical or clinical volume, program directors, chairpersons, attendings, fellows, and residents across the country have utilized the time to creatively address challenges both new and old. As this bloom of creativity has taken hold, we have witnessed increasing attention paid to resident education, trainee mental health, and the employment of new technologies. The advent of cross-institution collaborative lecture series such as UCSF COViD and EMPIRE has played a pivotal role in replacing lost clinical volume, and the publication of a number of studies addressing resident mental health provide reassurance that our wellness is not forgotten. The resources created during this time will have a lasting effect on resident education and continue to be useful in the years to come. Though the pandemic caused untold medical and economic hardship, perhaps these innovations will remain as a bright spot when regular operations resume.

\section{Compliance with Ethical Standards}

Conflict of Interest The authors have no conflicts of interest to report.

Human and Animal Rights and Informed Consent This article does not contain any studies with human or animal subjects performed by any of the authors.

\section{References}

Papers of particular interest, published recently, have been highlighted as:

- Of importance

- Of major importance

1. Goyal P, Choi JJ, Pinheiro LC, Schenck EJ, Chen R, Jabri A, et al. Clinical characteristics of Covid-19 in New York City. N Engl J Med. 2020;382:2372-4.

2. Rosen GH, Murray KS, Greene KL, Pruthi RS, Richstone L, Mirza M. Effect of COVID-19 on urology residency training: a nationwide survey of program directors by the Society of Academic Urologists. J Urol. 2020;204:1039-45. https://doi.org/10.1097/ JU0000000000001155.

3. Breazzano MP, Shen J, Abdelhakim AH, Dagi Glass L, Horowitz J, Xie SX, et al. New York City COVID-19 resident physician exposure during exponential phase of pandemic. J Clin Invest. 2020;130:4726-33. https://doi.org/10.1172/JCI139587.

4. Kwon YS, Tabakin AL, Patel HV, Backstrand JR, Jang TL, Kim IY, et al. Adapting urology residency training in the COVID-19 era. Urology. 2020;141:15-9.

5. Evgeniou E, Loizou P. The theoretical base of e-learning and its role in surgical education. J Surg Educ. 2012;69:665-9.

6. Reis LO, Ikari O, Taha-Neto KA, Gugliotta A, Denardi F. Delivery of a urology online course using Moodle versus didactic lectures methods. Int J Med Inform. 2015;84:149-54.

7. Henningsohn L, Dastaviz N, Stathakarou N, McGrath C. KIUrologyX: urology as you like it-a massive open online course for medical students, professionals, patients, and laypeople alike. Eur Urol. 2017;72:321-2.

8. Cohen SA. The AUA curriculum for medical students: current resources and developments. Curr Urol Rep. 2019;20:86-3.

9. Porpiglia F, Checcucci E, Amparore D, Verri P, Campi R, Claps F, et al. Slowdown of urology residents' learning curve during the COVID-19 emergency. BJU Int. 2020;125:E15-7.

10. Vargo E, Ali M, Henry F, Kmetz D, Drevna D, Krishnan J, et al. Cleveland Clinic Akron general urology residency program's COVID-19 experience. Urology. 2020;140:1-3.

11. Khusid JA, Weinstein CS, Becerra AZ, Kashani M, Robins DJ, Fink LE, et al. Well-being and education of urology residents during the COVID-19 pandemic: results of an American National Survey. Int J Clin Pract. 2020;382:e13559.

12. Tan YQ, Wang Z, Tiong HY, Chiong E. The good, the bad, and the ugly of the COVID-19 pandemic in a urology residency program in Singapore. Urology. 2020;142:244-5. https://doi.org/10.1016/j. urology.2020.05.027.

Publisher's Note Springer Nature remains neutral with regard to jurisdictional claims in published maps and institutional affiliations. 